\title{
Toward a New Model for Probabilistic Household Forecasts
}

Jiang Leiwen (Leiwen_Jiang@brown.edu)

Brian C. O’Neill (oneill@iiasa.ac.at)

\section{Approved by}

Wolfgang Lutz (lutz@iiasa.ac.at)

Leader, Population Project

October 16, 2003 Institute, its National Member Organizations, or other organizations supporting the work. 


\section{Contents}

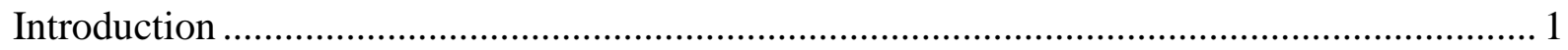

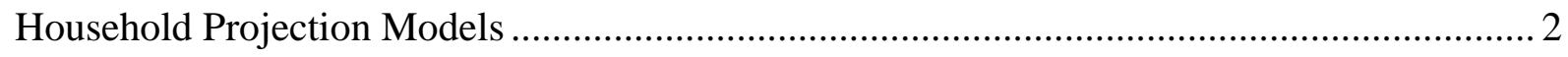

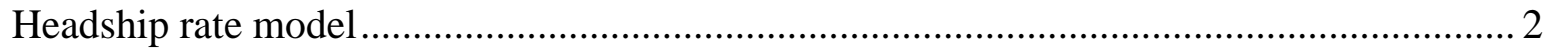

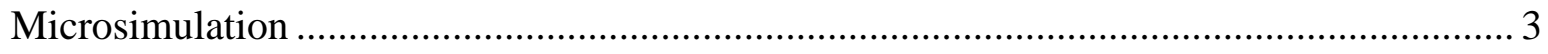

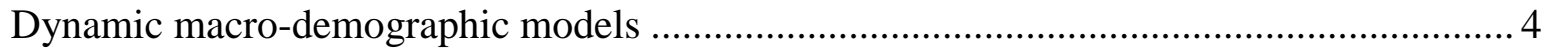

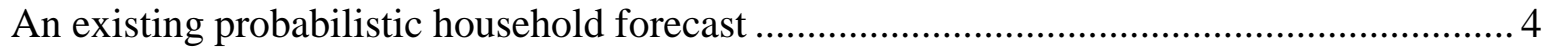

A New Approach - The Size/Age-Specific Headship Rates Model ....................................... 6

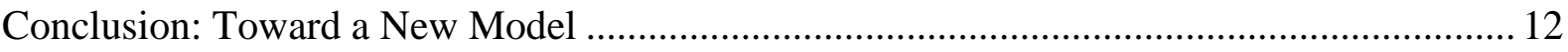

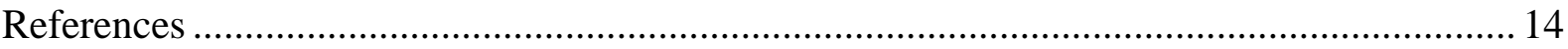




\section{Abstract}

Household projections are key components of analyses of several issues of social concern, including the welfare of the elderly, housing, and environmentally significant consumption patterns. Researchers or policy makers that use such projections need appropriate representations of uncertainty in order to inform their analyses. However, the weaknesses of the traditional approach of providing alternative variants to single "best guess" projection are magnified in household projections, which have many output variables of interest, and many input variables beyond fertility, mortality, and migration. We review current methods of household projections and the potential for using them to produce probabilistic projections, which would address many of these weaknesses. We then propose a new framework for a household projection method of intermediate complexity that we believe is a good candidate for providing a basis for further development of probabilistic household projections. An extension of the traditional headship rate approach, this method is based on modeling changes in headship rates decomposed by household size as a function of variables describing demographic events such as parity specific fertility, union formation and dissolution, and leaving home. It has moderate data requirements, manageable complexity, allows for direct specification of demographic events, and produces output that includes the most important household characteristics for many applications. An illustration of how such a model might be constructed, using data on the U.S. and China over the past several decades, demonstrates the viability of the approach. 


\section{Acknowledgments}

This paper has been submitted to the International Statistical Review for publication. An earlier version was presented at a workshop on "How to deal with uncertainty in population forecasting" held at the Vienna Institute of Demography, December 12-14, 2002, Vienna, Austria.

Jiang Leiwen's work was supported by a grant from the U.S. Department of Energy program on Integrated Assessment of Global Climate Change Research.

We thank Wolfgang Lutz for helpful conversations in formulating ideas for this paper. 


\section{About the Authors}

Jiang Leiwen is an Assistant Professor (Research) in the Global Environment Program at the Watson Institute for International Studies, Brown University, Providence, RI 02912, USA.

Brian C. O’Neill is a Research Scholar with the Population Project at IIASA. 


\title{
Toward a New Model for Probabilistic Household Forecasts
}

\author{
Jiang Leiwen and Brian C. O’Neill
}

\section{Introduction}

Anticipating changes in the number, size, and composition of households is an important element of many issues of social concern. For example, the living arrangements of the elderly are a key determinant of their needs for socioeconomic, physical and psychic assistance, and household projections are therefore critical to understanding challenges in this area (Gonnot et al. 1995; Bongaarts and Zimmer 2001). Similarly, several studies stress the importance of the household as a unit of consumption. Household members share living space, energy, water, and other goods, leading to potentially important economies of scale. Household composition, particularly by age, also affects consumption patterns (King 1999; Select Committee on Environment, Transport and Regional Affairs 1998; Van Diepen 1994, 1995; Martin 1999; Muller et al. 1999). Changes in consumption due to shifts in distributions of households by type can induce significant environmental pressure (MacKellar et al. 1995; Jiang 1999; O’Neill et al. 2001; Prskawetz et al. 2001; Liu et al. 2003; Keilman 2003).

No international organization produces household projections for countries or regions of the world, as is done for population by the United Nations, IIASA, the World Bank, and the U.S. Census Bureau. Rather, statistical offices of some individual countries produce their own projections to meet needs regarding housing demand, household services, or elderly support (King 1999; Hollmann et al. 2000).

Most existing household forecasts are based on a headship rate approach, in which an independent population projection is combined with a forecast of probabilities, by certain population subgroups, of heading households of different types. Household projections therefore must cope with uncertainty not only in the population projection, but also in the projection of headship rates. The most common approach is either to produce only a single best guess projection, or a small number of alternative variants (King 1999; Hollmann et al. 2000). However, the variants approach is not well suited for household forecasts. First, it is difficult to define variants for headship rates, because the link between demographic events which provide the theoretical basis for alternative variants - and the headship rates is unclear. Second, even if the household projections are performed with a more sophisticated method based directly on demographic events, the variant approach is unwieldy. There are many potentially relevant input variables that could be varied in alternative variants; in addition to total fertility (parity specific), mortality, and migration, other important factors are age at leaving home, and union formation and dissolution rates. It is not even clear which output variable should be used as the metric for the typical high/medium/low variants often produced in this approach. Should these be defined in terms of number of households, number of elderly households, age composition, multi-generation households, sex of household head, or what? Users have a range of different needs, and there is no single outcome that is of primary importance in all applications. Even if one were to select a single outcome as a basis for 
defining variants, the projection would be "probabilistically inconsistent" (Lee 1999) in that the highest variant in terms of that outcome would not be the highest variant in terms of others. In summary, the weaknesses of the traditional variants approach in population forecasting (Keilman 2003; Lee 1999; Alho 1998) are compounded for household forecasts.

Probabilistic household projections could address some of these problems. A single probabilistic projection accounting for uncertainty in the various demographic rates important to household dynamics would produce a distribution of outcomes that could be analyzed with respect to a number of different metrics. Just as a probabilistic population projection can produce consistent uncertainty distributions for population size and for age structure, a probabilistic household projection could produce consistent uncertainty distributions for household numbers, sizes, and age composition, all of which would also be consistent with the uncertainty distributions for population size and age structure. Probabilistic household projections would also be valuable to users who employ them in applied analyses that support decision-making. Quantification of the likelihood of various outcomes is valuable to formal decision analysis, as well as input to policy discussions (O'Neill 2003).

Probabilistic household projections would, however, be a formidable task. In addition to the methodological issues confronted by probabilistic population projections, they would also have to address new issues related to the additional variables and the demographic events and social processes they represent. We first briefly review current methods of household projections and the potential for using them to produce probabilistic projections. We also discuss the one existing probabilistic household projection in the literature (de Beer and Alders 1999; Alders 2001). We then propose a new household projection method of intermediate complexity that we believe is a good candidate for providing a basis for further development of probabilistic household projections. It has moderate data requirements, manageable complexity, allows for direct specification of demographic events, and produces output that includes the most important household characteristics for many applications.

\section{Household Projection Models}

Several different types of household projection models have been developed over the past few decades (Kuijsten and Vossen 1988). Econometric models (both static and dynamic) model the relationships between household characteristics and socioeconomic, cultural, and environmental determinants. Examples include the Cornell model in the USA (Caldwell et al. 1979), the UPDATE model for households in small areas in England (Duley et al. 1988), and the NEDYMAS model in the Netherlands (Nelissen and Vossen 1989). However, these models are much less developed in terms of household structures than purely demographic models. Our interest here is in models capable of producing at least a modest set of household characteristics as output, so we focus our discussion on three types of purely demographic models: headship rate models (static macro-demographic models), microsimulation models, and dynamic macro-demographic models.

\section{Headship rate model}

The headship rate method involves extrapolating proportions of household heads in population categories defined by certain combinations of age, sex, and possibly marital status. The headship rate projections are combined with an independent projection of the population by age and sex (and marital status) to produce a projection of households broken down by demographic characteristics of the head of the household. 
Three different methodologies for projecting headship rates have been used: (1) linearly or exponentially extrapolating these changes into the future; (2) using regression models of the relationships between headship rates and major socioeconomic factors combined with projections of those factors; and (3) developing scenarios based on information on government policies, such as housing policy for the elderly or for university students.

Projections of headship rates are intended to represent the results of dynamic demographic processes; however, the demographic processes themselves remain black boxes. Thus it is very difficult to incorporate demographic assumptions about future changes in demographic rates such as fertility, marriage, divorce, and mortality into the headship rate projections. Nevertheless the headship rate method is often used, because it is easy to apply and its data demands are modest. Over the past few decades, household projection models have been predominantly of the headship rate type.

A headship rate method is an attractive option as a basis for probabilistic projections given its limited data demands, relative simplicity, and manageable number of variables. Headship rate models could be made probabilistic by combining probabilistic population projections with probabilistic projections of the headship rates, perhaps defined using some combination of time series models, ex-post error analysis, and expert judgment. The task would be challenging, given the large number of rates that would need to be projected. Each age- and sex-specific headship rate would need its own forecast, particularly since changes in rates can vary strongly across groups. For example, headship rates changed the most in the older age group, particularly among women, between 1940 and 1980 in the U.S. (Kobrin 1973; Carliner 1975; Sweet 1984).

Moreover, assumptions about the covariance of changes in the components and headship rates, across age and sex groups, and between the forecast years would need to be made. While statistical analysis of relationships between the components and headship rates would be possible, it would be more direct to analyze relationships between the components and the household-related demographic rates (union formation and dissolution, leaving home) themselves, and the results would be easier to assess. For example, the correlation between headship rates and fertility is not straightforward. Low fertility is often associated with the postponement of marriage. If the age at leaving home is also postponed, headship rates would decline; if not, they would increase due to increasing numbers of young single adults. Thus it would be preferable to explicitly include in a household projection assumptions regarding changes in the age at leaving home and age at marriage, rather than to directly model the relationship between fertility and headship rates.

\section{Microsimulation}

Microsimulation household models are virtually probabilistic (Hammel et al. 1976; Wachter 1987; Smith 1987; Galler 1988; Nelissen 1991; Oskamp 1997). These models take individuals as the unit of analysis, simulate each demographic event, and determine the changes in individual status usually using Monte Carlo methods combined with probability distributions for transition rates (Wachter 1998). The model has major advantages in studying the variability of individuals and their distributions across households. For example, this method is especially well suited for studying kin networks, in which available kin may or may not live together in a household. Goldstein and Wachter (2001) recently applied a new method of using contemporary survey data as a basis for projecting spouse and sibling ties differentiated by educational level and race. Limitations of the method include the very large data 
requirements, and the fact that the simulation itself often must include a very large "population" of individuals to reduce sampling error.

\section{Dynamic macro-demographic models}

In dynamic macro-demographic models, the unit of analysis is the group, e.g., an age and parity class or all households of a given type. Transition matrices are used to update the composition of the population by group over time (Keilman et al. 1988). Prominent examples include the LIPRO Model developed by Van Imhof and Keilman (1991). LIPRO projects a large number of household types and accounts for many types of demographic events; however, data on transition probabilities (and projections of their changes) among 69 types of events that individuals may experience are necessary. These data have to be collected in a special survey because they are not available in the conventional demographic data sources.

The ProFamy model developed by Zeng et al. (1997) takes a somewhat different approach that extends Bongaarts' nuclear status life table model. ProFamy only requires data that can usually be obtained from conventional demographic data sources. The model uses the individual as the unit of forecast; all individuals are classified according to eight dimensions of demographic status. Projections are performed based on status transition rates, and then distributions of households by size and type are derived based on characteristics of reference persons (or household 'markers') in a manner that produces consistent projections of households and individuals. Since 1997, ProFamy has been used to produce household forecasts for Germany, the U.S. (Zeng et al. 1999), China (Jiang 1999), and Austria (Prskawetz et al. 2001).

Probabilistic projections based on macro-dynamic household models would be possible by defining uncertainty distributions for the transition rates. The main challenge would be the very large state space such projections would need to cover. For example, the transition rates rely on standard schedules defined by age-, sex-, (sometimes parity- and marital-status-) specific rates for mortality, first marriage, parity specific fertility, migration, leaving parental home, divorce, remarriage by the divorced, and remarriage by the widowed. Deriving probability distributions for all of these events, given limited data on many events, would be problematic, as would accounting for possible correlations among events.

Nonetheless, the macro-demographic approach is attractive in that it allows the application of available data, and of expert opinion, directly to demographic events themselves rather than to indirect measures such as headship rates. One possibility for managing the large state space is to simplify the model by only retaining the demographic events that the household projection in a given setting is most sensitive to. For example, fertility and leaving home are the most important for household formation in developing countries like China, while marriage and union dissolution are important for some developed countries.

\section{An existing probabilistic household forecast}

The only existing probabilistic household forecast was made by de Beer and Alders at Statistics Netherlands (de Beer and Alders 1999; Alders 2001) for the Netherlands up to year 2050. The Statistics Netherlands household forecasting model in general is an approach somewhat between a headship rate model and a macro-dynamic model. It consists of four steps: 
1. Project the population by age, sex and marital status;

2. Assume future trends in household position rates distinguished by age, sex and marital status, for six household positions: living at the parental home, living alone, living with a partner, being a single parent, living in an institution, and other;

3. Based on the results of steps 1 and 2, calculate the number of persons by age, sex and household position;

4. Calculate the number of households by assuming that persons living alone and lone parents count for one household, persons living with a partner count for a half household, and children living with their parents and people living in an institution count for no households.

Uncertainty in the future number of households is derived by defining uncertainty distributions for household position rates in the year 2050, and interpolating between the resulting population distributions by household position and current conditions. Obviously, the different position rates are not independent: if people within a given population group are more likely to occupy a certain position in a household, then they must be less likely to occupy others. The authors approach this problem by defining uncertainty distributions for each position rate in a step-wise fashion.

- First, an assumption is made about the probability distribution for living in an institution. Conditional on that assumption, and the distribution of population by age and sex, the uncertainty distribution for rates of (and total population) living in private households by age and sex are calculated.

- $\quad$ Second, an uncertainty distribution for the rates of leaving parental home is assumed; combined with the distribution of population living in private households, this yields an uncertainty distribution for the population leaving parental home.

- $\quad$ Third, given the uncertainty distribution for the population leaving parental home, the uncertainty distribution for the probability of living alone is assumed. The rest of the people are mainly persons living with a partner.

For the year of 2050, the uncertainty distributions for the percentage of the population in the different household positions are derived by repeated draws from these underlying uncertainty distributions. Perfect correlation across ages and sex is assumed. Each draw yields the number of persons by age, sex and household position, and then the number of households. The percentages for years between the baseline and 2050 are interpolated, implying perfect autocorrelation.

Results show that in 2050 the $67 \%$ uncertainty interval ranges from 7.5 million to 9 million. The width of this interval is smaller than that between deterministic high and low variants from Statistics Netherlands. While de Beer and Alders (1999) presents only the uncertainty in total numbers of households, uncertainty intervals for average household size and for population (and proportions) by five household positions (living alone and lone parent are combined) are also available from this model (M. Alders, personal communication).

This approach has the advantage of combining assumptions about demographic events with household formation and dissolution, while avoiding the problem of requiring large amounts of data unavailable from conventional demographic sources. However, the principal limitation is that while it provides abundant information on the population in different household positions, it produces limited information about household types and size. For many users, the most important information from a household forecast is the number of households, the distribution of households by size, and the distribution of households by age 
of the householders, especially for application to analysis of consumption (MacKellar et al. 1995; Jiang 1999; O’Neill and Chen 2002; Prskawetz et al. 2001; Karl 2000).

\section{A New Approach - The Size/Age-Specific Headship Rates Model}

We propose a new method of making household forecasts that extends the traditional headship rate method. Instead of applying total age-specific headship rates to the future population, the new method applies age-specific headship rates decomposed by household size. In addition, changes in these age- and size-specific headship rates are modeled as functions of the demographic processes to which they are most sensitive. This method has the advantages that (1) it produces output on future changes in household numbers, size distributions, and distributions by the age of the householder, which have been identified as the most useful characteristics in applied problems; (2) it explicitly models the relationships between demographic events and headship rates, rather than treating them as a "black box"; and (3) it is simple enough that the resulting model could be used as the basis for more computationally intensive applications, such as probabilistic projections, or integrated assessments of interdisciplinary issues. 

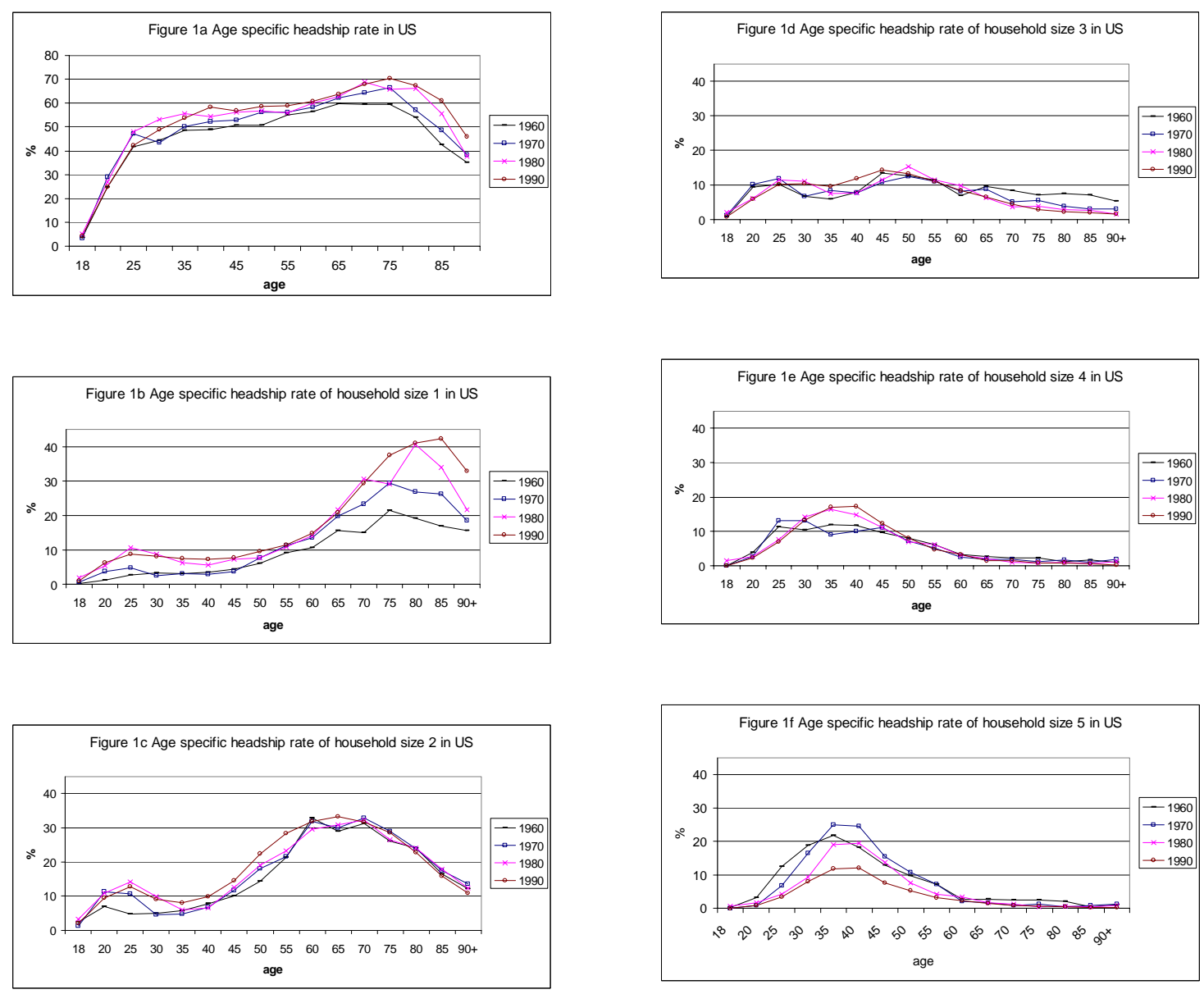

Figure 1. Age-specific headship rate by household size in the U.S., 1960-1990.

We illustrate the new approach with the cases of the U.S. and China. Using census data, we analyze the changes in age-specific headship rate by household size for the period 1960-1990 in the U.S. and 1982-2000 in China (Figures 1 and 2). We describe observed changes in rates, and propose qualitative explanations for these changes in terms of trends in specific demographic events. We argue that these explanations provide a strong basis for specification of a model of size-specific headship rates and describe a model framework in terms of key variables likely to explain most of the changes in these rates. This framework could be used as the basis for a new household projection model and estimated from data and from the results of more complex projection models.

Figures 1a and 2a show that the total age-specific headship rates for the U.S. and, especially, for China have been quite stable over the past decades. In the U.S., headship rates have increased somewhat over this period, but the general age pattern has not changed much. There are clear differences across countries: China has lower headship rates beyond about age 55, and before age 35 . The lower headship rate in early adulthood 
is driven primarily by later age at leaving parental home compared to most Western countries. The low rates at older age groups are a result of the preference for living with an adult child (mostly a son). After retirement, Chinese elderly usually pass on the household head title to their adult children, resulting in a significant decrease of headship rate in older age groups. In contrast, most American elderly continue to head a household so that headship rates increase until age 75 .

Figure 2. Age-specific headship rate by household size of China, 1982-2000.
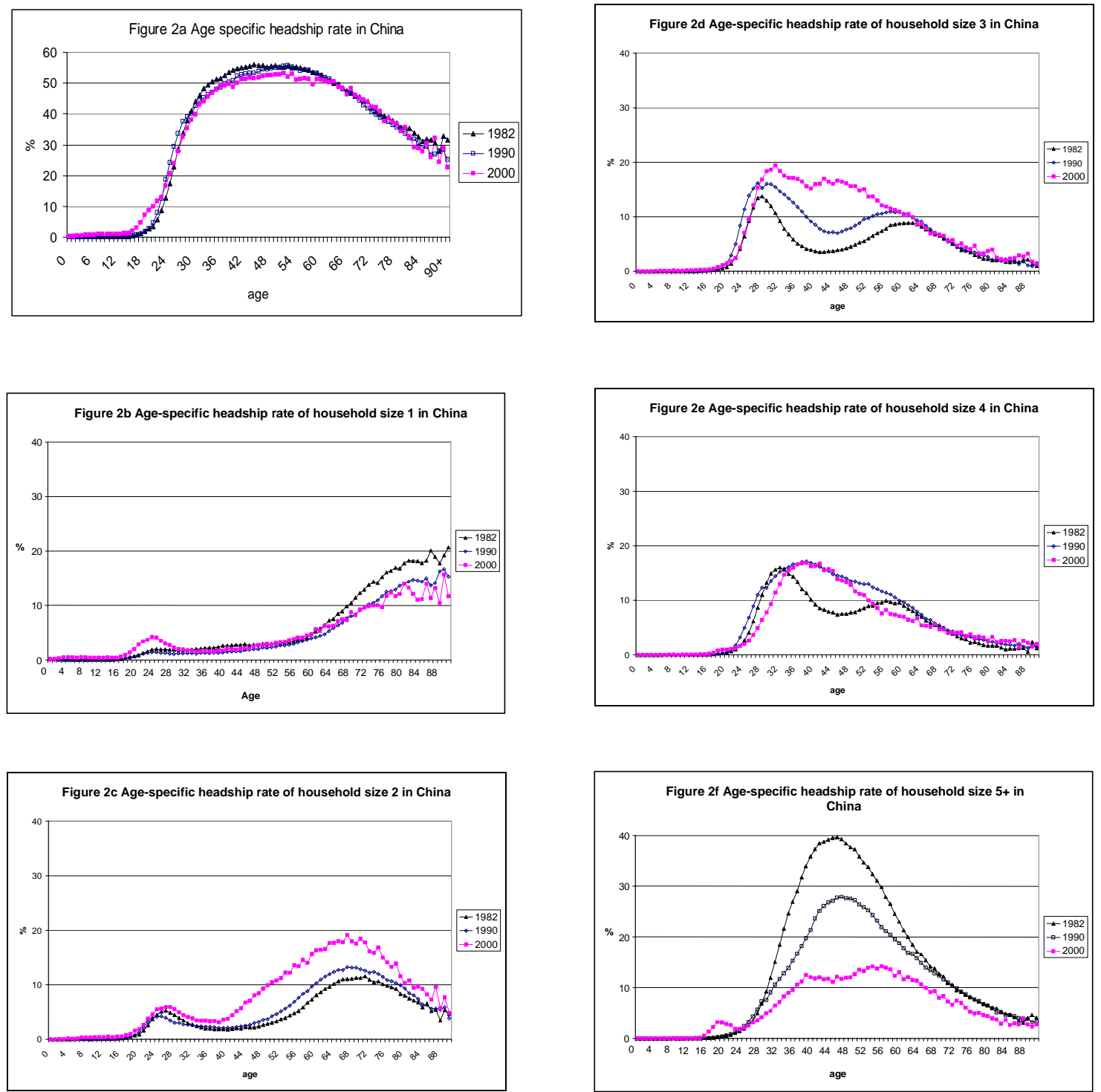
The relative stability of total headship rates in both countries masks the fact that there have been substantial changes in the propensity of household formation and household dissolution over the past few decades. Figures 1 and 2 show that size-specific headship rates in the U.S. and China have changed considerably, especially in China. These changes have been driven by trends in demographic rates such as fertility, mortality, union formation and dissolution, and leaving home. We argue that changes in headship rates for each household size are traceable to trends in particular kinds of demographic rates, and thus make a theoretically grounded basis for a projection model.

Before considering each household size in turn, note that in general, the headship rates for different sizes display clear overall age patterns in both the U.S. and China. For one- and two-person households, the headship rate is high for the elderly above age 60 and for young adults below age 30 . For households with three or more members, the headship rates are low in young adult age groups, increase and reach a peak for the age group 30-45, then decrease and become very small for the oldest old.

For households of size 1, the shape of the age-specific headship rate curve at younger ages is determined primarily by the age-specific rates at which children leave parental homes, and the age-specific rates of marriage and divorce. At older ages, changes in life expectancy and the changes in the gender disparity of life expectancy are probably the primary determinants of the shape of the curve, with smaller contributions from changes in the divorce/remarriage rate and in preferences for living independently from children.

Figure 1 indicates that headship rates in the U.S. increased the most for households of size 1 over the period of 1960-1990. The increase is especially significant among the elderly. We hypothesize that changes in life expectancy have been the primary reason. In the U.S., life expectancy at birth increased from 69.9 to 75.4 between 1960 and 1990. By itself, this improvement would be expected to be associated with a greater likelihood of living with a spouse at older ages; all else equal, this would actually decrease headship rates of one-person households. However, at the same time life expectancy was increasing, the difference in life expectancy between men and women increased as well, from 6.6 to 7.1 years over the same period. The difference in remaining life expectancy at age 65 increased even more, from 2.8 to 3.9 years (Federal Interagency Forum on Aging-Related Statistics 2002). The trend toward larger gender differences would be expected to lead to increased numbers of single person households. Rates of union dissolution have increased over this period and have likely contributed to the change in headship rates as well. The divorce rate (number of divorces per 100 existing marriages) increased from 9\% in 1960 to 21\% in 1987 (Popenoe 1993); the proportion of a given marriage cohort that voluntarily ends their union was around $33 \%$ in the middle of the century, but increased to more than 50\% in the end of 1980s (Furstenberg 1990). Increasing union dissolution would lead to larger number of people entering the older age groups without a spouse, and thus more likely to be living alone. Lastly, improvements in the health and financial status of older Americans may have led to a continuation of a trend toward preferences for living independently at older ages. At the beginning of the $20^{\text {th }}$ century, more than 70 percent of people aged 65 or older resided with kin. By 1980, only 23 percent of elderly lived with relatives (Bianchi and Casper 2000). Older Americans now are more likely to spend their later years with spouse or living alone than with adult children.

Changes in the one-person household headship rate at younger ages have likely been driven by changes in the age at leaving home (an event which tends to create one-person households), and the age of union formation (an event which tends to reduce the number of one-person households). Before 1950, most young Americans left their parental home for or after marriage. Since then, more and more young people leave home for education, employment or simply for increased independence. At the same time, Americans were 
significantly postponing marriage. In 1960, only 10 percent of women ages 25 to 29 had never married. By the end of the century, more than $40 \%$ of women in that age group had not been married, and the majority (52\%) of men were still unmarried at these ages (Bianchi and Casper 2000). The combined effect of these trends led to increases in the one-person headship rate between 1960-1980. During the 1980s, there was a slight decrease in the headship rate for young adults. This occurrence actually strengthens the case for ascribing changes to changes in leaving home and union formation/dissolution. During that decade, the average age of leaving parental home increased and the proportion returning to parental home increased, because of the increase in housing prices and improved standards of living in the parental home (Goldscheider et al. 1999). Similarly, the divorce rate has declined since the early 1980s (Bianchi and Casper 2000); given that most divorces happen among young couples below age 30 , this trend counteracts the effects of later marriage.

Trends in China for one-person headship rates at older ages were opposite to the general trend in the U.S., showing a decrease in the period 1982 to 2000 (Figure 2). This trend is consistent with the observed increase of life expectancy over this period (from 67.8 to 70.0), coupled with no change in the gender difference in life expectancy. Since divorce rates have not changed substantially, and neither have preferences (the elderly still prefer to live with children, particularly in rural China), these two factors did not influence one-person headship rates as they probably did in the U.S. The observed increase in the headship rate in younger age groups most likely resulted from a trend toward more and more young people leaving the parental home for the purpose of education, jobs, or for independence.

For two-person households, changes in the rate and mean age of marriage (for single people) and of first birth and divorce (for married couples) are the primary determinants of the shape of the headship rate curve in the early adulthood group. For the late-middle aged group, changes in the propensity of leaving parental home may affect the headship rate when there is only one child remaining in a household. At older ages, mortality is the prime determinant.

In the United States, although the two-person headship rate did not change much for the elderly, it increased somewhat for other age groups, most likely due to the lengthening of the interval between marriage and first birth (Morgan 1996). Another reason may be the increase in the divorce rate, which one would expect to create a larger number of single parent households with one child. An increase in non-marital fertility may also have played a role (Popenoe 1993).

In China, there was a striking increase in the two-person headship rate above age 40, especially between 1990 and 2000. This trend is likely a reflection of the increasing number of children establishing their own nuclear households, leaving parents behind in an "empty nest". At older ages, this reflects the improvement in mortality, which prolongs the period during which both spouses are living together.

For households of size 3 , the shape of the headship rate curve in the childbearing age groups changes with fertility of parity 1 and 2, both of which can affect the headship rate in either direction depending on the number of parents in the household. Union dissolution rates will also affect headship rates for this size household, as will changes in the propensity of leaving parental home.

In the U.S., the three-person headship rate decreased for older age groups due to the increasing propensity of children to leave the parental home and of the elderly to live independently from their children. Changes at younger ages are subtler. One identifiable trend is the shift in the first peak in headship rates from the mid-20s age group to the early 30s age group (a second, slightly larger peak follows in the mid to late 40s). This shift is likely due to the increase in the mean age of first births. The probability of completing first birth by women 
aged 35 decreased from more than $45 \%$ in the 1950s to less $30 \%$ in the 1970s (Morgan 1996). The slight dip in the headship rate after this initial peak is due largely to second births, and the second peak after age 45 is due to the first children leaving home.

Changes in the headship rate for size 3 in China have been quite different. The most important change has been the large increase in the headship rate for the middle age groups, due to an increasing proportion of couples with only one child since the early 1980s. A second change has been first an increase (during the 1980s) and then a decrease (during the 1990s) of the headship rate in the early 20s age group. This pattern likely reflects the trend toward younger marriage and earlier first births in the 1980s, as the family planning policy of "Later marriage, longer birth interval, and fewer children" implemented in the 1970s was relaxed, and then a reversal toward later marriages and first births during the 1990s due to socioeconomic and cultural changes supporting these trends.

For four-person households, changes in fertility at parity 2 and 3 are the main determinant of changes the pattern of headship rate. For example, in the U.S., the peak in the headship rate curve increased in magnitude and shifted from occurring in the mid to late $20 \mathrm{~s}$ in the 1960s and 1970s, to the mid to late 30s in the 1980s and 1990s. This change was driven by a shift to later second births and a dramatic decrease in the probability of giving third births (Morgan 1996).

In China the headship rate increased in the middle age groups due to a decline in the probability of third births, especially in rural areas during the 1980s. The headship rate declined during the 1990s for people aged 25-35 because young couples increasingly had only one child. Headship rates also declined in the 1990s for the late middle age and early old age groups, most likely due to the growing number of first children moving out for job opportunities and education.

The headship rate pattern for size $5+$ is driven largely by fertility of parity $3+$ and the propensity of leaving parental home. For example, the U.S. generally experienced a large decrease in headship rates, and a shift in the peak rate to older ages. This pattern reflects later childbearing, along with a sharp decline in fertility since the end of 1960s. Increasing union dissolution and early ages at leaving home have also contributed.

In China, there have been very large decreases in the 5+-person headship rate over the past 20 years, due to rapid fertility declines. However, there is a small increase of headship rate for ages 16-24, a result of an increase in the number of young people leaving parental home for jobs and education, and sharing living space in order to reduce the expense of housing.

In summary, the evolution of age patterns of size-specific headship rates has a clear connection to the changes of demographic events. The opposite approach, tracing the impacts across household sizes of given demographic events, can also give insight into the functional relationships between events and headship rates.

For example, changes in parity-specific fertility affect headship rates for different sized households in a number of ways, as we have discussed. The increase in fertility of first births will change the headship rate for the childbearing age group (15-49) as follows: decrease headship rates of size 1 (as single parents have a child and become two-person households), increase headship rates of size 2 for single parent households (the consequence of the first effect), decrease headship rates of size 2 for two-parent households, and increase headship rates of size 3 of two-parent households. Effects of fertility by parity on headship rates for all household sizes are summarized in Table 1. 
Table 1. Impacts of the increase in the total fertility rate on headship rates, while all else is equal.

\begin{tabular}{lccc}
\hline Headship rate & \multicolumn{3}{c}{ Parity } \\
& 1 & 2 & 3 \\
\hline Household size 1 & $-(15-49,1$ parent $)$ & No effect & No effect \\
Household size 2 & $+(15-49,1$ parent $)$ & $-(15-49,1$ parent $)$ & No effect \\
& $-(15-49,2$ parents $)$ & & \\
Household size 3 & $+(15-49,2$ parents $)$ & $+(15-49,1$ parent $)$ & No effect \\
Household size 4 & No effect & $+(15-49,2$ parents $)$ & $+(15-49,1$ parent $)$ \\
& & & $-(15-49,2$ parents $)$ \\
Household size 5+ & No effect & No effect & $+(15-49,2$ parent $)$ \\
\hline
\end{tabular}

Similarly, the impacts of increasing divorce rates on the age patterns of size-specific headship rates are summarized in Table 2. Empirical studies indicate that the divorce rate is the highest among those aged 25-35. Young heads with no children tend to have less stable marriages than those who have children. Therefore, an increase in the divorce rate will increase headship rates of size 1 for the young age group, decrease headship rates of size 2 for young couples without children, increase headship rates of size 2 for single parents with one child, and decrease headship rates of size 3 for couples with one child.

Table 2. Impact of the increase in divorce rate on headship rates while else is equal.

\begin{tabular}{ll}
\hline Household Size & Effect on headship rate in young age group \\
\hline 1 & + \\
2 & - (couple with no child) \\
3 & + (couple with one child) \\
$\ldots$ & - (couple with one child) \\
\hline
\end{tabular}

\section{Conclusion: Toward a New Model}

These examples strongly suggest that, based on current understanding and empirical data, changes in the age patterns of size-specific headship rates can be modeled by parameterizing the changes for different age groups as a function of the dynamics of important demographic events. We propose that age- and size-specific headship rates are best modeled as the sum of three functions, one describing each of three broad age categories that serve as proxies for different life cycle stages: young adulthood, middle age, and elderly. Thus, the starting point for our basic model, based on our preliminary analysis for the U.S. and China, is:

$$
h(i, x)=g_{1}(i, x)+g_{2}(i, x)+g_{3}(i, x)+\varepsilon(i, x)
$$

where $\mathrm{h}(\mathrm{i}, \mathrm{x})$ is the headship rate for household size $\mathrm{i}$ at age $\mathrm{x}, \mathrm{g}(\mathrm{i}, \mathrm{x})$ is a function capturing effects acting mainly on one of three broad age categories (1=young adult; $2=$ middle age; $3=$ elderly), and $\varepsilon$ is an error term. In turn, 


$$
g(i, x)=f\left(r_{1}, r_{2}, r_{3}, \ldots .\right)
$$

where $r_{n}$ is a variable describing a particular demographic rate. The demographic rates that we expect to influence each of our three "g" functions are given in Table 3, which summarizes the discussion in the previous section.

Table 3. Demographic events and parameters of importance to a model of size-specific headship rates.

\begin{tabular}{|c|c|c|c|}
\hline \multirow[t]{2}{*}{ Household Size } & \multicolumn{3}{|c|}{ Demographic events and parameters } \\
\hline & Early adulthood group & Middle age group & Senior age group \\
\hline 1 & $\begin{array}{l}\text { Propensity of leaving } \\
\text { home, age and rate of } \\
\text { marriage, divorce rate }\end{array}$ & $\begin{array}{l}\text { Marriage, remarriage } \\
\text { and divorce rate, } \\
\text { propensity of leaving } \\
\text { home }\end{array}$ & $\begin{array}{l}\text { Mortality, propensity of } \\
\text { leaving home }\end{array}$ \\
\hline 2 & $\begin{array}{l}\text { Age and rate of marriage, } \\
\text { age and rate of first birth, } \\
\text { divorce rate }\end{array}$ & $\begin{array}{l}\text { Propensity of leaving } \\
\text { home, divorce rate, } \\
\text { mortality }\end{array}$ & $\begin{array}{l}\text { Mortality, propensity of } \\
\text { leaving parental home }\end{array}$ \\
\hline 3 & $\begin{array}{l}\text { Fertility rate of first and } \\
\text { second birth, divorce rate }\end{array}$ & $\begin{array}{l}\text { Propensity of leaving } \\
\text { home, divorce rate }\end{array}$ & $\begin{array}{l}\text { Mortality, propensity of } \\
\text { leaving home }\end{array}$ \\
\hline 4 & $\begin{array}{l}\text { Fertility rate of second } \\
\text { and third birth, divorce } \\
\text { rate }\end{array}$ & $\begin{array}{l}\text { Fertility of second and } \\
\text { third birth, propensity } \\
\text { of leaving home }\end{array}$ & $\begin{array}{l}\text { Mortality, propensity of } \\
\text { leaving home }\end{array}$ \\
\hline$\ldots$ & $\ldots$ & $\ldots$ & $\ldots$ \\
\hline
\end{tabular}

Existing empirical data will likely be insufficient to estimate all model parameters, given that the household formation and dissolution involves many demographic events, and data for some events are unavailable in conventional population data sources. Thus, it would likely be necessary to use "synthetic data" generated from a more complex household projection model, such as existing dynamic household models. For example, one strategy would be to generate a number of scenarios that systematically vary different demographic rates, and observe the effect on size-specific headship rates. Model parameters could then be estimated from this "data". The end result would be a reduced-form model with parameters estimated such that it reproduced the behavior of the more complex model, and could be tested against empirical data for specific countries.

Our extension of the headship rate approach is amenable for use in probabilistic forecasting because it reduces the complexity of the model (compared to full macrodemographic household models) while retaining demographic processes as important inputs to which expert opinion and other forms of information can be applied in order to develop forecasts. For example, in this model one might specify probability distributions not only for fertility, mortality, and migration, but also for variables such as the mean age at leaving home, mean ages of parity-specific births, and rates and mean ages of marriage and divorce. Judgment, supported by empirical analysis, would also need to be applied to the correlation matrix. For example, in many countries changes in age at marriage are likely to be correlated with changes in age at first birth, and fertility may be correlated with mean age at leaving home. Careful attention would need to be paid to these possibilities. 
Here we have presented the basic model framework, and used data to support our argument regarding its viability. Clearly, further work is required to develop a first illustrative model for testing. However, our analysis demonstrates one plausible strategy for achieving the goal of probabilistic household projections.

\section{References}

Alders, M. 2001. Huishoudensprognose 2000-2050: Veronderstellingen over onzekerheidsmarges. Maandstatistiek van de bevolking Jaargang 49 (August) (in Dutch).

Alho, J.M. 1998. A Stochastic Forecast of the Population of Finland. Helsinki: Statistics Finland.

Bianchi, S.M. and L.M. Casper. 2000. American families. Population Bulletin 55(4).

Bongaarts, J. and Z. Zimmer. 2001. Living arrangements of older adults in the developing world: Analysis of DHS household surveys. Policy Research Division Working Paper No. 148. New York: Population Council.

Caldwell, S.B., W. Greene, T. Mount, S. Saltzman, and R. Broyd. 1979. Forecasting regional energy demand with linked macro/micro models. Papers of the Regional Science Association 43: 99-113.

Carliner, G. 1975. Determinants of household headship. Journal of Marriage and the Family 37(1): 28-38.

de Beer, J. and M. Alders. 1999. Probabilistic population and household forecasts for the Netherlands. Paper for the European Population Conference, August 30 - September 3, 1999, The Hague, The Netherlands.

Duley, C., P. Rees, and M. Clarke. 1988. A microsimulation model for updating households in small areas between census. Paper presented at the NIDI/RUU workshop "Multistate demography: measurement, analysis, forecasting," October 31 - November 4, 1988, Zeist, The Netherlands.

Federal Interagency Forum on Aging-Related Statistics. 2002. http://www.aoa.dhhs.gov/agingstats

Furstenberg, F.F., Jr. 1990. Divorce and the American family. Annual Review of Sociology 16.

Galler, H. 1988. Microsimulation of household formation and dissolution. Pages 139-159 in N. Keilman, A. Kuijsten, and A. Vossen (eds.), Modelling Household Formation and Dissolution. Oxford, U.K.: Clarendon Press.

Goldscheider, F., C. Goldscheider, P. St. Clair, and J. Hodges. 1999. Changes in returning home in the United States, 1925-1985. Social Forces 78(2).

Goldstein, J. and K. Wachter, 2001. Survey-based stochastic kinship forecasting. Paper presented at the General Conference of IUSSP, August 2001, Salvador, Brazil.

Gonnot, J.-P., N. Keilman, and C. Prinz, Eds. 1995. Social Security, Household and Family Dynamics in Aging Societies. Boston: Kluwer Academic Publishers.

Hammel, E., D. Hutchinson, K. Wachter, R. Lundy, and R. Deuel. 1976. The SOCSIM demographic-sociological microsimulation program. Research Series No. 27. Berkeley, CA: Institute of International Studies, University of California. 
Hollmann, F.W., T.J. Mulder, and J.E. Kallan. 2000. Methodology and assumptions for the population projection of the United States: 1999 to 2100. Working Paper No. 38. Washington, D.C.: Population Division, U.S. Census Bureau.

Jiang, L. 1999. Population and Sustainable Development in China - Population and Household Scenarios for Two Regions. Amsterdam: Thelasis.

Karl, G. 2000. Human Settlement Statistics. New York: United Nations Center for Human Settlements (UNCHS).

Keilman, N. 2003. The threat of small households. Nature 421(6922): 489-490.

Keilman, N., A. Kuijsten, and A. Vossen, Eds. 1988. Modelling Household Formation and Dissolution. Oxford, U.K.: Clarendon Press.

King, D. 1999. Official household projections in England: Methodology, usage and sensitivity tests. Paper presented at "Joint ECE-EUROSTAT Work Session on Demographic Projections, May 3-7, 1999, Perugia, Italy.

Kobrin, F.E. 1973. Household headship and its changes in the United States, 1940-1960, 1970. Journal of the American Statistical Association 68(344): 793-800.

Kuijsten, A. and A. Vossen. 1988. Introduction. Pages 3-12 in N. Keilman, A. Kuijsten, and A. Vossen (eds.), Modelling Household Formation and Dissolution. Oxford, U.K.: Clarendon Press.

Lee, R.D. 1999. Probabilistic approaches to population forecasting. Pages 156-190 in W. Lutz, J.W. Vaupel, and D.A. Ahlburg (eds.), Frontiers of Population Forecasting. A Supplement to Vol. 24, 1998, Population and Development Review. New York: Population Council.

Liu, J., G. Daily, P. Ehrlich, and G. Luck. 2003. Effects of household dynamics on resource consumption and biodiversity. Nature 421(6922): 530-533.

MacKellar, F.L., W. Lutz, C. Prinz, and A. Goujon. 1995. Population, households and $\mathrm{CO}_{2}$ emissions. Population and Development Review 21(4): 849-865.

Martin, N. 1999. Population, households and domestic water use in countries of the Mediterranean Middle East. Interim Report IR-99-032. Laxenburg, Austria: IIASA.

Morgan, P. 1996. Characteristic feature of modern American fertility. Pages 19-63 in the Supplement "Fertility in the United States: New Patterns, New Theories." Population and Development Review 22. New York: Population Council.

Muller, C., K.S. Gnanasekaran, and K. Knapp. 1999. Housing and Living Arrangements of the Elderly, An International Comparison Study. New York: International Longevity Center - USA, Ltd. Almanac Phase 4.

Nelissen, J. 1991. Household and education projections by means of a microsimulation model. Economic Modelling 8(4): 480-511.

Nelissen, J. and A. Vossen. 1989. Projecting household dynamics: A scenario-based microsimulation approach. European Journal of Population 5(3): 253-279.

O'Neill, B.C. 2003. Conditional probabilistic population projections: An application to climate change. Interim Report IR-03-51. Laxenburg, Austria: IIASA.

O'Neill, B.C. and B.S. Chen. 2002. Demographic determinants of household energy use in the United States. Pages 53-88 in W. Lutz, A. Prskawetz, and W.C. Sanderson (eds.), 
Population and Environment. Methods and Analysis. A Supplement to Vol. 28, 2002, Population and Development Review. New York: Population Council.

O'Neill, B.C., F.L. MacKellar, and W. Lutz. 2001. Population and Climate Change. Cambridge, UK: Cambridge University Press.

Oskamp, A. 1997. Local Housing Market Simulation: A Micro Approach. Amsterdam: Thesis Publishers.

Popenoe, D. 1993. American decline, 1960-1990: A review and appraisal. Journal of Marriage and the Family 55(3): 527-542.

Prskawetz, A., L. Jiang, and B. O’Neill. 2001. Demographic composition and projections of car use in Austria. Paper presented at the General Conference of IUSSP, August 2001, Salvador, Brazil.

Select Committee on Environment, Transport and Regional Affairs. 1998. Tenth Report. London: The United Kingdom Parliament.

Smith, J.E. 1987. The computer simulation of kin sets and kin counts. Pages 249-266 in J. Bongaarts, T.K. Burch, and K.W. Wachter (eds.), Family Demography: Methods and their Application. Oxford, U.K.: Clarendon Press.

Sweet, J.A. 1984. Components of changes in the number of households: 1970-1980. Demography 21(2): 129-140.

Van Diepen, A. 1995. Population, land use and housing trends in the Netherlands since 1950. Working Paper WP-95-63. Laxenburg, Austria: IIASA.

Van Diepen, A. 1994. Demografische ontwikkelingen en milieugebruik. Pages 357-374 in N. van Nimwegen and G. Beets (eds.), Bevolkingsvraagstukken in Nederland Anno 1994: Demografisch Ontwikkelingen in Maatschappelijk Perspectief. NIDI Report No. 35. The Hague, the Netherlands: NIDI (in Dutch).

Van Imhoff, E. and N. Keilman. 1991. Lipro 2.0: An Application of a Dynamic Demographic Projection Model to Household Structure in The Netherlands. Amsterdam/Lisse and Berwyn PA, Swets \& Zeitlinger Inc.

Wachter, K. 1998. SOCSIM: Description of the Program, http://demog.berkeley.edu.

Wachter, K. 1987. Microsimulation of household cycles. Pages 215-227 in J. Bongaarts, T.K. Burch, and K.W. Wachter (eds.), Family Demography: Methods and their Application. Oxford, U.K.: Clarendon Press.

Zeng, Y., J.W. Vaupel, and Z. Wang, 1999. Household projection using conventional demographic data. Pages 59-87 in W. Lutz, J.W. Vaupel, and D.A. Ahlburg (eds.), Frontiers of Population Forecasting. A Supplement to Vol. 24, 1998, Population and Development Review. New York: Population Council.

Zeng, Y., J.W. Vaupel, and Z. Wang. 1997. A multidimensional model for projecting family households - with an illustrative numerical application. Mathematical Population Studies 15(3): 187-216. 